Letras, Lima, Univ. San Marcos. 63 (91): 64-80, 1992.

\title{
Soberanía y sumisión en "Los gallimazos sin plumas" de Julio Ramón Ribeyro
}

\section{INTRODUCCION}

SANTIAGO LOPEZ MAGUIÑA

Los relatos de Los gallinazos sin plumas primer libro de cuentos de Julio Ramón Ribeyro, publicado en 1955, refieren al universo urbano que presenta Lima de los años cincuenta. Desde un primer momento se ve que el enunciador de los textos pretende mostrar

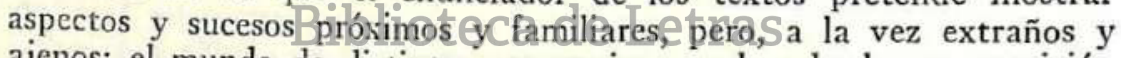
ajenos; el mundo de distintos personajes que han hecho su aparición al transformarse la capital del Perú en una urbe industrializada y extendida; de seres maltratados e insatisfechos, arrojados de los espacios donde la vida se desarrolla con opulencia, o al menos con bienestar y seguridad.

El primer cuento cuyo título sirve también de rótulo al libro, presenta con nitidez y riqueza los rasgos sintácticos y semánticos que se destacan como los más constantes de la serie. Esa pudo haber sido la razón por la cual se lo eligió para inaugurar el volumen, pero esa es la razón por la cual se lo elige ahora como objeto de análisis.

\section{LAS RELACIONES DE PODER}

Entre los personajes principales de "Los gallinazos sin plumas", el abuelo "don Santos" y sus nietos "Efraín y Enrique", se destaca una relación de dominio. En una relación de ese tipo uno de los personajes, el más débil o, en todo caso, el que hubiera resultado derrotado en una confrontación, está obligado a entregar al otro, al más pode- 
roso o al triunfador, un objeto de valor que posee y que aquél desea para sí. En este relato los nietos, personajes dominados por el abuelo, no poseen objetos de valor externos a sí mismos. Lo único que tienen es su propia fuerza de trabajo. No pueden, en consecuencia, transferir a su antecesor nadia que no sea su energía laboral.

La situación de dominio en la que los nietos se encuentran no es, por otro lado, fruto de una lucha. No se ha produćido entre ellos y su abuelo un enfrentamiento. Su estado de dominio es un estado dado. Pero si se examinan las cosas con un poco más de atención se observará que se trata con más exactitud de un estado establecido por el orden social. Por una instancia no manifiesta de manera antropomorfa que opera como un Destinador de órdenes o mandamientos, según una de las cuales, es obligatorio que en el marco de una relación familiar los pequeños deban obediencia a sus mayores.

Por eso, sí "Efraín y Enrique" trabajan para su abuelo es porque existe una exigencia social de acatamiento a lo que el viejo ordena.

Simultáneamente si los nietos deben obediencia a su antecesor, éste, a su vez, está forzado por el mismo Destinador no antropomorfo (que se puede figurativizar en las "costumbres" o en la "cultura") a intervenir para producir un estado de bienestar en aquéllos. Está obligado no sólo a mantenerlos, sino también a procurarles afecto y seguridad. Pero "don Santos" no exidencia cumplir con esa prescripción social. Unicamente lleva a cábo las funciones que tienen que ver con los roles de un personaje que domina, manda y exige. En relación a su nietos actúa casi en forma exclusiva como dominador. Recíprocamente, los niños, respecto a su abuelo actúan en lo funda-

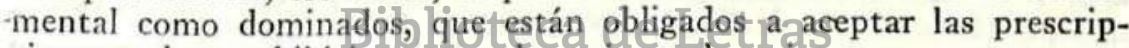
ciones y las prohibiciones que les asigna el anciano.

El abuelo cumple confa exffencia social celemandar, de prescribir, prohibir, permitir y facultar. Pero, por otra parte, infringe la obligación de intervenir a fin de lograr el bienestar de sus nietos. De esa manera es un personaje que se halla tanto en armonía y en acuerdo con el orden establecido, así como en discordia y en oposición. En la ubicación de un actor que manda desarrollar una actuación socialmente permitida. En la posición de un actor que debe porcurar la satisfacción de sus descendientes desarrolla, en cambio, una actuación prohibida.

Se ha dicho que mandar a sus nietos cómo intervenir en bien de ellos son actuaciones asignadas por la costumbre, por las normas sociales y culturales establecidas. Pero la primera es una operación de ejecución simple. Corresponde a la realización directa de una prescripción, a su cumplimiento sin resistencias. En tanto que la segunda constituye una operación compleja, que puede entrañar una oposición.

El acto de mandar al parecer no supone tomar previamente una decisión. El abuelo no tiene que elegir entre hacerlo o no. La intervención en favor de los niños, en cambio, debería suponer una previa 
toma de decisión. Es decir, suponer un conflicto, una confrontación. A la obligación de intervenir para bien de los chicos debería de oponerse un deseo contrario, un deseo de no intervención, que debería producir a su vez el efecto de un sentimiento de culpa, de un reproche de conciencia. Sin embargo tal efecto no tiene lugar, puesto que para el abuelo no parece existir la obligación de intervenir. De modo tal que se coloca en una posición de indiferencia personal en relación con esa obligación.

Hay que suponer que dicha posición desde el punto de vista del orden cultural (de las "costumbres"), del Destinador no antropomorfo, es una situación que implica una condena. Por tanto "don Santos" recibiría una doble sanción: el reconocimiento como sujeto de mando, la condena como sujeto de la indiferencia.

Ahora bien, si el abuelo está obligado y autorizado a mandar, los nietos están obligados a obedecer. Y del mismo modo que la acción de mando, la obediencia es una actuación simple. Los niños ante la obligación social de obedecer no oponen resistencia Asumen una posición de sumisión sin conflicto.

\section{LOS DESEOS}

¿Cuál es el desarrollo de las actividades volitivas de los sujetos a los que vincula una relación de dominio/sumisión? En este tipo de relación imperan abiertamente los anhelos y aspiraciones del sujeto dominador. No faltan, sin embargo, búsquedas que puede emprender el sujeto dominado. Pero ellas son ocultas y secretas, como ocurre con las pretenciones ide "Efraír a Enrique"teng relato que estudiamos, cuyos respectiyos deseos esconden declarar, y descubrir ante su

La mayor aspiración que manifiesta el abuelo es ganar dinero. Este no es un objeto buscado para adquirir otro valorativamente más elevado. El dinero es una finalidad en sí. "Don Santos" no es, sin embargo, un personaje capaz de obtener lo que quiere por sí mismo. Es un hombre viejo y lisiado, que tiene una pierna de madera.

Pero en cambio es poseedor de un cerdo con cuya venta puede ser realizado su deseo. Este graciosamente es llamado "Pascual" y es evidente que en el resaltan los valores de lo/comestible/y lo/deleite/. No obstante lo cual no cuenta de entrada con valores suficientes y definitivos como para ser comercialmente transferido. Para ello necesitar alcanzar un mayor volumen. Su adecuado valor transaccional es considerado en términos cuantitativos: cuánta carne y cuánta grasa puede proporcionar.

La condición valorativa para la venta del cerdo es de esa manera su /gordura/. De allí que sí el valor-dinero es el objeto de búsqueda mente que onseguir para lograr la venta. El recorrido narrativo co- 
rrespondiente al engordamiento será justamente el recorrido sintagmáticamente más importante del relato.

No es "don Santos", sujeto que quiere que el cerdo engorde, quien hace lo necesario para proporcionarle los alimentos que han de engordarlo, es decir, que logra la valoración del objeto de uso. No es un personaje competente económicamente. No es capaz de comprar alimentos completos y maduros. $\mathrm{Ni}$ restos de comida, que pudieran habérsele ofrecido. Pero tampoco tiene la competencia física como para buscar por sí mismo los restos con que, de acuerdo a los elementos que ofrece el texto, se alimenta un cerdo, cuando se carece de dinero.

Sin embargo, gracias a la posición que ocupa, de sujeto de mando, puede disponer de la fuerza laboral de sus nietos. El viejo es incapaz en lo físico y en lo económico, pero en cambio tiene el poder socialmente reconocido de mandar y ser obedecido: un poder del que puede disponer para la realización de sus propios fines.

¿Dónde consigue "restos de comida" quien no tiene poder económico? En los cubos de basura.

\section{4. "CUBO DE BASORA": "CAJA DE SORPRESAS"}

..."Un cubo de basura es siempre una caja de sorpresas. Se encuentran latas de sardinas, zapatos viejos, pedazos de pan, pericotes muertos, algodones inmundos. A ellos sólo les interesa los restos de comida. En el fondo del chiquero, Pascual recibe cualquier cosa y tiene predilección por las verduras ligeramehte desconpuestas (e) tomates podridos, pedazos de cebgo extrañas salsas que no figuran en ningún manual de comiad. No es raro, sin embargo, hacer un hallazgo valioso. Un día Efraín encontró unos tirantes con los que fabricó una honda. Otra vez una pera casi buena que devoró en el acto. Enrique, en cambio, tiene suerte para las cajitas de remedios, los pomos brillantes, las escobillas de dientes usadas y otras cosas semejantes que colecciona con avidez" (p. 6).

Un "cubo de basura" es asemejado a una "caja de sorpresas", pues en él pueden ser hallados objetos inesperados de diversa naturaleza. Su contenido está formado de los más distintos elementos y materiales que no parecen tener relaciones ni vínculos inmediatos entre sí, que se encuentran en un estado de mezcla y confusión, lo que manifiesta una inexistencia de reglas de organización o el desconocimiento de las mismas. En este sentido la "basura" es también una figuración extraña. Sin embargo, esa visión corresponde a un observador ajeno y distante. Un personaje que tiene una relación más próxima y familiar, 
como "Efraín y Enrique", puede ver en el montón confuso de cosas un orden. Primero, que no todos los objetos son iguales. Los hay casi completos, casi plenos, como "una pera casi buena" y no es imposible que pudieran encontrarse objetos plenos. Se encuentran asimismo objetos descompuestos: "verduras ligeramente descompuestas", "tomates podridos", etc. Productos orgánicos que sufren un proceso material de deterioro y putrefacción. Por otra parte, se pueden hallar diversos tipos de objetos inorgánicos, cuya condición parece presentar un estado que no es ni completo ni descompuesto. Son unidades depredadas, falladas, pero no en un grado absoluto.

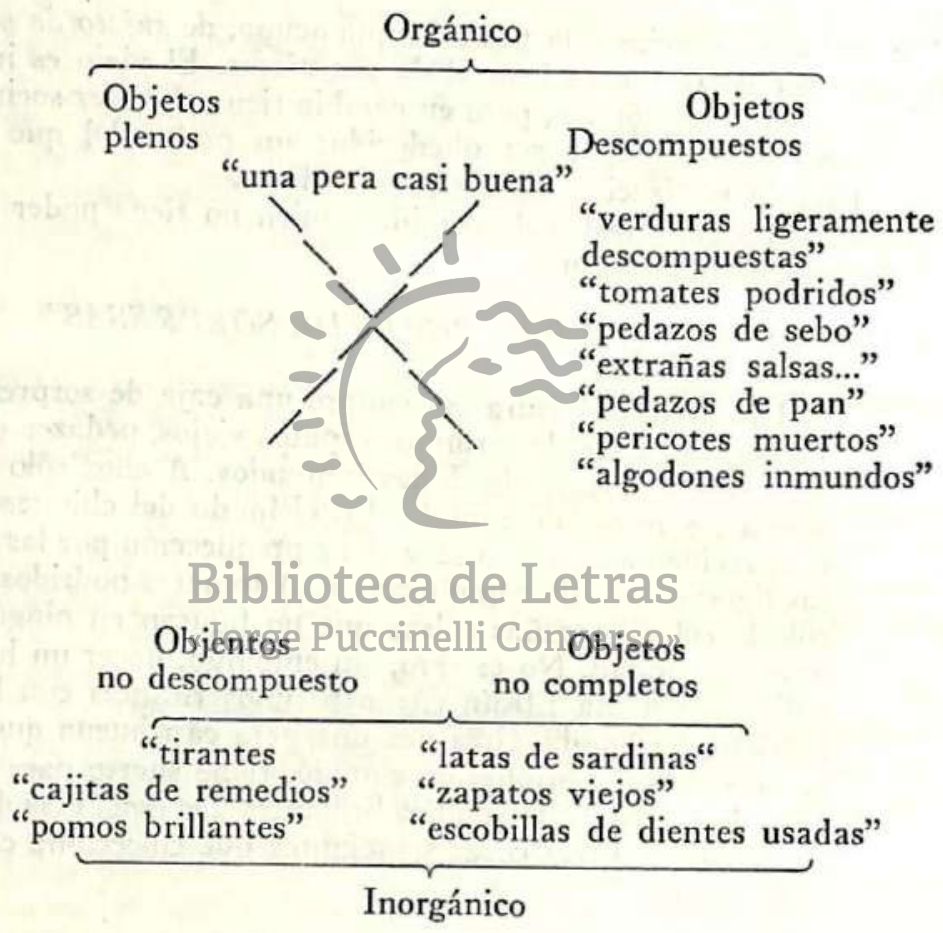

[cuadro $\mathrm{n}^{\circ}$ 1]

Esos objetos pueden ser organizados en un cuadro de relaciones (cf. cuadrado No 1). En él se observa la presencia de dos categorías opuestas: lo orgánico vs lo inorgánico, la primera de las cuales, que tienen un carácter positivo, correlaciona dos términos contrarios, pero que mantienen al mismo tiempo entre sí una relación gradual, ya que de uno a otro se desarrolla un proceso de deterioro, un proceso regresivo, de descomposición. La segunda categoría correlaciona en cambio 
dos términos que forman una unidad semántica de tipo complejo. Los elementos que constituyen esta categoría son lógicamente opuestos, pero al mismo tiempo son semánticamente equivalentes, dentro del marco figurativo de un basurero, porque tanto uno como otro no se hallan sometidos a un proceso de descomposición similar al que ocurre con los elementos orgánicos. Lo descompuesto no deviene necesariamente no completo. Al mismo tiempo uno y otro elemento no se excluyen. La presencia de uno no marca la ausencia del otro. Ambos pueden manifestarse en forma simultánea.

Este es un cuadrado trazado desde la perspectiva de "Efraín y Enrique" y supone una valoración cuantitativa de los objetos: los términos del esquema califican el grado de completud de los objetos. Las mismas unidades, desde la perspectiva de los productores de basura, de las familias que habitan "casas elegantes", en la medida que constituyen un conjunto heteróclito, desordenado, caótico, no reciben una valoración cuantitativa. La totalidad es calificada de /expulsable/. Efectivamente la basura está formada de elementos rechazados, juzgados inútiles, aunque pudieran hallarse en su interior objetos plenos, virtualmente útiles.

Se destaca, al lado de la valoración cuantitativa, otra red de valores, que marcan el uso de/los objetos contenidos en un "bote de basura". Es el siguiente:

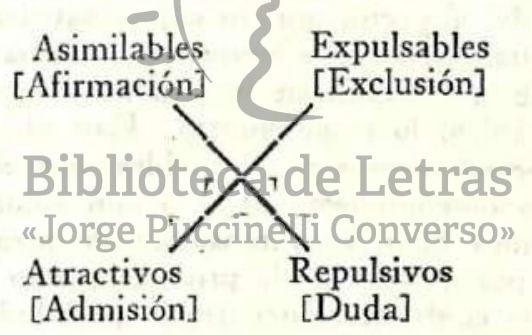

[cuadro $n^{\circ}$ 2]

Aquí se registran valores referidos a la asimilabilidad, expulsabilidad, atractivo y repulsivilidad de los objetos en relación a los sujetos. Puede decirse que tienen un carácter epistémico. En este sentido el valor de lo asimilable afirma la positividad de un objeto, mientras que la expulsabilidad el rechazo, la exclusión.

Estos valores son atribuidos a los objetos de distinto modo, según cual sea el sujeto que se los asigne, en función de sus intenciones (intereses) particulares. Para los nietos los objetos orgánicos plenos tienen un valor/asimilable/, mientas que los objetos orgánicos descompuestos tienen un valor/repulsivo/. Estos siguen un proceso de putrefacción, que produce efectos de repugnancia y de exclusión. Los objetos 
no descompuestos y no incompletos parecen tener un valor /atractivo/ $\mathrm{y} /$ asimilable/. Y se puede señalar que entre los objetos asimilables puede reconocerse una subdivisión: lo /comestible/ y lo /incomestible/.

Para el abuelo es /asimilable/ y /domestible/ lo que tiene tal valor para su cerdo. Es decir los objetos orgánicos descompuestos, que son /repulsivos/ y /expulsivos/ para sus nietos. Mientras que los objetos inorgánicos no son /atractivos/ ni /repulsivos/. Son objetos indiferentes, que no interesan, que no se destacan a la mirada y que, en consecuencia, no se valorizan. Son objetos de los que no se quiere saber.

$\mathrm{Ha}$ de observarse por tanto que en relación a los objetos en un "cubo de basura" se presentan en la instancia narrativa tres actos valorativos, realizados por tres sujetos distintos, respectivamente. El primer lugar tenemos el acto valorativo realizado por los productores de "basura" y sus delegados, quienes /expulsan/ y /repulsan/ la totalidad de los objetos en ella contenidos, hacen de la "basura" en conjunto un objeto abyecto. En segundo lugar está la valoración que hace de los objetos "don Santos" quien de acuerdo a sus intenciones valora positivamente de /atractivo/ y /asimilable/ lo /comestible/ para su cerdo. Por último se tiene la valoración que hacen "Efraín y Enrique", ya antes descrita. Interesa poner de relieve la trama de atracciones y repulsiones, de incorporaciones y expulsiones que se teje en torno a la "basura". En general la "basura" es um excedente, un resto inútil, un objeto expulsado, abyecto, por un sujeto satisfecho. Está formado por una variedad heteróclita de objetos, como se ha visto, pero se destacan los rasgos de la descomposición orgánica, lo pútrico y de la descomposición inorgánica, lo fragmentario. Esos objetos abyectos pueden en cambio serBatrayentes Qasihilables.pos sujetos no satisfechos. Lo orgánico descompuesto atras como valor en sí, por su carácter lúdico. Ahơra Gien, esas tensiones de atracción y repulsión, mente valorizada por quienes no la producen, pero la requieren. Aquí entonces surge una confrontación entre lo prohibido y lo requerido y necesitado, que ha de tratarse después.

\section{LA MONSTRUOSIDAD}

La búsqueda de "restos de comida" puede ser percibida desde dos perspectivas valorativas distintas. Desde la perspectiva de los niños la búsqueda no constituye una tarea fácil ni simple. Es en primer lugar una actividad exploratoria y selectiva, que requiere de un cierto saber adquirido por la experiencia. Es en segundo lugar una actividad en cierto modo riesgosa. No porque la vida sea puesta en peligro, sino porque implica la posibilidad de un enfrentamiento contra personajes que obstaculizan e interrumpen su labor. Conviene leer al respecto el 
siguiente fragmento en el que se describe la actividad que los muchachos llevan a cabo:

"Después de una rigurosa selección regresaba la basura al cubo y se lanzaban sobre el próximo. No conviene demorarse mucho porque el enemigo siempre está al acecho. A veces son sorprendidos por las sirvientas y tienen que huir dejando regado su botín. Pero, con más frecuencia, es el carro de la Baja Policía el que parece y entonces la jornada esta perdida"

Por lo cual no siempre su actividad es satisfactoria. Pero lo que hay que destacar es que se trata de una actividad práctica, que supone el ejercicio de un poder. Aunque ha de anotarse que no de una manera abierta, sino secreta y camuflada, pues los niños pugnan por recoger restos evadiendo la mirada de sus posibles antagonistas. Su labor es prohibida y condenada por el orden social imperante. Hay que observar que la actividad que desarrollan los niños es una actividad impuesta, ordenada por su abuelo, quien suponemos sabe que es prohibida. De esta manera dicho personaje ejecuta un rol de desobediencia contra el orden establecido, a la vez que fuerzáa a sus nietos a efectuarla en lo ilegal.

Desde el punto de vista de "don Santos", "Efraín y Enrique" siempre deben llevar comida para el cerdo. El incumplimiento de la orden es condenado y castigado, sin atenuantes, los que, por otro lado, no existen para el viejo. Los posibles abstáculos no son tomados en cuenta. El incumpliniseintol de to prdenado es atribuido a una falta cumeticla por los niños. Si no han recobido la comida requerida se entien-

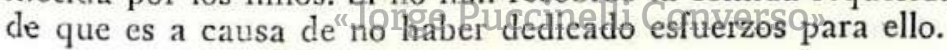

..."la mayoría de las veces (el abuelo) estallaba:

- ¡Idiotas! ¿Qué han hecho hoy día? ¡Se han puesto a jugar seguramente!

¡Pascual se morirá dehambre!”

Así si por una parte el viejo impone a los niños una tarea que es contraria a las normas sociales dominantes, por otra parte, no reconoce el trabajo por ellos realizado y nos les retribuye debidamente. Peor todavía: condena y castiga sus faltas sin reparos. Exige el cumplimiento absoluto de una actividad socialmente prohibida, sin compensación alguna. Simultáneamente, castiga sin miramientos las no realizaciones.

La valoración del cumplimiento de la ctividad que realizan los pequeños depende del grado de satisfacción del animal, que decrece, por otra parte a medida que engorda y se aproxima al estado que hará posible su venta. La gordura que va consiguiendo le cerdo lo va hacien- 
do cada vez más valioso. Pero, a la vez, el mismo proceso lo va convirtiendo en un personaje, por una parte, vulnerable, que puede morir de hambre si no son satisfechas sus necesidades, desde el punto de vista del abuelo y, por otra parte, "casi monstruoso", El cerdo presenta marcas de irregularidad en las dimensiones acrecentadas de su tamaño y en la alta intensidad de sus gruñidos:

"Al comenzar el invierno el cerdo estaba convertido en una especie de monstruo insaciable. Todo le parecía poco y don Santos se vengaba en sus nietos del hambre del animal. Los obligaba a levantarse más temprano, a invadir los terrenos ajenos en busca de desperdicios. Por último los forzó a que se dirigieran al muladar que estaba al borde del mar.

-Allí encontrarán más cosas. Será más fácil además porque todo está junto" (p. 7).

Más adelante se encuentra la siguiente manifestación de la monstruosidad:

"La voracidad del cerdo crecía con su gordura. Gruñía por las tardes con el hocico enterrado en el fango. Del corralón de Nemesio, que vivía a una cuadra se había venido a quejar" (p. 11).

La monstruosidad se expresa aquí en tres rasgos exagerados: en la "voracidad", la "gordura" y los gruñidos cada vez más altos. La "voracidad" y los "gruñidos" manifiestan especialmente un estado de creciente insatisfacciob, mientras queda "gordurg" manifiesta una creciente valoración economica. Esos procesos figurativos pueden ser destacados en el siguienté esquería!nelli Converso"

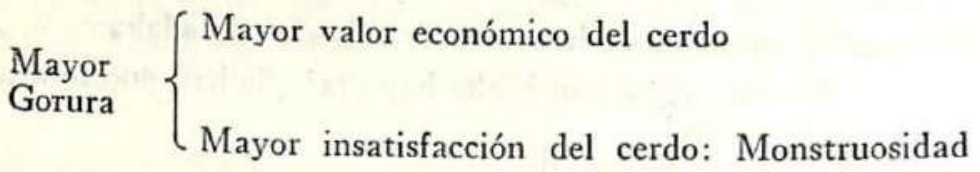

A la mayor gorura le corresponde un mayor valor económico y, por otro, una mayor insatisfacción, a la cual corresponde, a su vez, la manifestación de la monstruosidad. La insatisfacción y la monstruosidad son configuraciones, de otra parte, paralelas y recíprocas.

Ahora bien, la mayor gordura produce en el abuelo el efecto simultáneo de una mayor y una menor expectativa de venta. Mayor, porque el incremento volumétrico del cerdo lo aproxima al estado ideal de su venta. Menor, porque el mismo incremento que reduce el grado de satisfacción alimentaria del animal, lo convierte en un personaje vulnerableble y lo aleja del estado ideal de venta: 


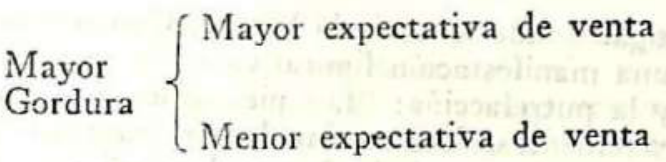

La doble expectativa da lugar a un aumento de tensión volitiva, a una presión tendiente a la realización de lo buscado y a otra tendiente a la eliminación del temor a la no realización ${ }^{1}$. La mayor expectativa produce ya una cierta manifestación de euforia, mientras que la menor expectativa produce el efecto de un esttado de disforia. Por eso la primera permite proyectar la posible realización de lo querido, mientras que la segunda proyecta una imposible realización. Dicho de otro modo: una posible falta o insatisfacción, que da lugar a la actuación agresiva del abuelo: "don Santos se vengaba en sus nietos del hambre del animal".

La venganza y el castigo que les infringe se traduce en una mayor obligación de trabajo, cuyo objeto además tiende a ser valorativamente más degradado (desde un punto de vista natural y cultural: más descompuesto orgánicamente y más excluidos culturalmente) y riesgoso de obtener: "Los obligaba a levantarse más temprano, a invadir terrenos ajenos en busea de desperdicios. Por último los forzó a que se dirigieran al muladar".

\section{LA "PRECIOSA SUCIEDAD"}

"Los carros de la Baja Policía, siguiendo una huella de tierra, descargaban la basura sobre una pendiente de piedras. Visto dese el el mratecóm el muladar formaba una especie de acantilado oscuro y humenante, donde los gallinazos y los perros se desplazaban como hormigas. "Desde lejos los muchachos arrojaron piedras para espantar a sus enemigos. Un perro se retiró aullando. Cuando estuvieron cerca sintieron un olor anuseabundo que penetró hasta sus pulmones. Los pies se les hundían en un alto de plumas, de excrementos, de materias descompuestas o quemadas. enterrando las manos comenzaron la exploración. A veces, bajo un periódico amarillento, descubrían una carroña devorada a medias. En los acantilados próximos los gallinazos espiaban impacientes $y$ algunos se acercaban saltando de piedra en piedra, como si quisieran acorralarlos. Efraín gritaba para intimidarlos y sus gritos resonaban en el desfiladero y hacían desprenderse guijarros que rodaban hasta el mar. Después de una hora de trabajo regresaron al corralón con los cubos llenos.

-¡Bravo! -exclamó don Santos-Habrá que repetir estos dos o tres veces po semana". (pp.7-8). 
Un muladar es un lugar donde se vacía la basura. Con respecto a este objeto se presenta una manifestación figurativa en la que se destaca la descomposición y la putrefacción: "Los pies se les hundían en un alto de plumas, de excrementos, de materias descompuestas o quemadas". Es un conjunto formado por deshechos y desperdicios repulsivos y rechazados, asociados a lo excrementicio.

El texto muestra el muladar como si sólo estuviera constituido por elementos orgánicos. No se menciona ninguna materia de tipo inorgánico. Se enfatiza únicamente la presencia de objetos orgánicos en los últimos grados de descomposición. En oposición la basura reune, en cambio, objetos aun semidescompuestos, que permiten valorarlos de no totalmente repulsivos ni expulsivos.

Se ha visto que la búsqueda y selección de objetos comestibles para el cerdo constituye una tarea competitiva cuando se exploran "cubos de basura", pues los pequeños exploradores tiene que enfrentarse a empleados domésticos y a los trabajadores de la Baja Policia, que obstaculizan e impiden el buen logro de sus actividades. Ahora se puede ver que la recolección de restos en el "muladar" se presenta también en principio como una actividad competitiva. Pero en este caso los antagonistas sor animales: "gallinazos y perros", aves de rapiña que se alimentan de carroña y caninos vagos, sin dueño, a los cuales es posible ahuyentar con facilidad. Sin embargo hay que apuntar que las empleadas y los trabajadores de la Baja Policía no son propiamente hablando competidores que disputan los restos de comida que buscan los muchachos. Ellos no pretenden apropiarse de los desperdicios. Si estorban y complican su tarea es por deber. Tanto unas como otros cumplen con elrol de prohibines impedir que lo contenido en un "cubo de basura" sea usado. Lo allí reunido está valorizado por la sociedad de no asimilable y expulsivo y se condena la posibilidad de su empleo. A las empleadas y a la Baja Policia se los puede ver como delegados, que han sido encomendados a mantener esa valoración y a castigar a quienes se permiten lo contrario.

Los animales que pululan en el "muladar", en cambio, sí tienen la condición de rivales. Ellos sí pretenden los mismo objetos. Puede decirse, por esa razón, que se trata de personajes equivalentes, aunque los niños no acuden al "muladar" para encontrar los "restos" que ellos quieren. Ellos van a ese lugar por obligación. Obedeciendo una orden. De todas formas van por los "desperdicios" a causa del valor comestible que tienen para "Pascual", es decir, con la finalidad de obtener algo de importancia, útil y asimilable.

Las empleadas y la Baja Policia impiden la recolección de "restos" porque se ha asignado a éstos una condición excluyente absoluta. Porque se les ha conferido valores (más propiamente hablando antivalores) de excedencia, que los convierte en objetos inútiles y degradados. Al contrario, los muchacos acuden al "muladar" por una razón 
opuesta. Se dirigen allí para acopiar objetos que se consideran útiles y asimilables. En este sentido compiten y rivalizan con los animales. Pretenden lo mismo, aunque esa es una pretención que constituye un deber, no un querer. Por esa razón, al compartir la búsqueda de un mismo objeto con "galinazos" y con "perros", se hacen personajes equivalentes. Sin embargo, es preciso señalar que dicha equivalencia resulta de la voluntad del "abuelo", "Efraín y Enrique" no desean revolver la basura maloliente del "muladar" en pos de "desperdicios". Hacen eso por delegación obligatoria de "don Santos", que por tanto, es el que permite que sus nietos realicen una actividad que los coloca en una posición similar a la de los "gallinazos" y los "perros".

"Efraín y Enrique (...)). Pronto formaron parte de la extraña fauna de esos lugares y los gallinazos, acostumbrados a su presencia, laboraban a su lado, graznando, aletenando, escarbando con sus picos amarillos, como ayudándolos a descubrir la pista de la preciosa suciedad" (p. 8).

Los hermanos llegan al "muladar" como competidores, pero después la frecuencia y la repetición de surtarea recolectora los convierte en parte de la "extraña fauna" de animales rapaces que allí pululan. La confrontación que separa a éstos de aquéllos termina pronto y surge algo parecido a la cooperación. En la dimensión del parecer los animales se muestran a la vista del lector como ayudantes y cooperadores de "Efraín y Enrique", que les facilitan "a descubrir la pista de la preciosa suciedad".

Puede elaborarselun lesquema dedas ptincipales configuraciones destacadas en esta sección: Puccinelli Converso»

\section{degradación}

recorrido de 1) menor putrefacción $\longrightarrow$ 2) mayor putrefacción ["bote de basura"] ["muladar"]

$\overbrace{\rightarrow \text { animalización }}^{\rightarrow}$

\section{EL DERECHO DE POSEER: DERECHO DE QUERER}

A la realización de las intenciones de venta se oponen en el relato dos recorridos narrativos: el de la disminución física de los niños y el de la afirmación de un derecho de posesión. El primero de ellos corresponde a una pérdida de poder. A la privación de la capacidad de recoger "desperdicios". El segundo al de la asunción de una pretención, esto es, de querer. 
Ambos tienen como efecto la reducción de las expectativas volitivas del abuelo, el aumento de la insatisfacción y el descontento, $\mathrm{y}$, en consecuencia, el incremento de la agresión contra sus nietos. Debe apuntarse que la cólera y la agresividad desencadenados no son producidas, desde el punto de vista del anciano, por la pérdida efectiva de poder físico, que resultan de una herida accidental y una enfermedad gripal, de la que son presa "Efraín y Enrique". Para "don Santos" si los niños no cumplen con hacer lo que les ordena es a causa de que no quieren. El malestar que los aqueja, la debilidad que los afecta son "patrañas", constituyen una mentira. Desde esa perspectiva la cólera y la agresividad son el efecto de un acto de desobediencia. El anciano no concibe que sus nietos dejen de cumplir la tarea encomendada por razones ajenas a su voluntad. No es capaz de ver por eso el hecho práctico de la disminución de su poder fisico, de su imposibilidad fáctica de realizar lo que les ordena.

La hostilidad del viejo es verbal y es práctica. La agresión verbal consiste de la atribución de calificativos degradantes: en la asignación del valor de la /suciedad/, ligada a la /descomposición/ y a la /podredumbre/ : “Mugre, nada más que mugre!”, "Ustedes son basura, nada más que basura!" y en la asignación del valor de la /animalidad/, asociada también a la /descomposición/y a la /podredumbre/; “i(...) pobres gallinazos sin plumas!". Mientras que la agresión práctica consiste de un castigo: no proporcionarles comida, suspender el ejercicio del poder de mantenerlos. Aquí hay que anotar que los muchachos habían ya adquirido previamente los valores de la / podredumbre/ y de la /animalidad/ por contigüidad. Por su contacto con objetos pútridos y la equivalente astividad desarrollada con "perros sarnosos" y aves de rapiña, buscando "desperdicios" en el muladar. De acuerdo a esta anotación se observa. qued Pagresión liverbal vesinea sanción que el abuelo atribuye a sus nietos, apareciendo como sujeto Destinador de los estados de /animalidad/ y / podredumbre/. Esto es, condena lo que ha hecho posible. Pero actua como si no lo supiera.

La asunción de una pretención: la del derecho de los nietos a tener un perro, aparece también, desde el punto de vista de "don Santos" como un acto de desobediencia, contrario a la inteción de vender a su cerdo. El derecho de posesión que los niños reclaman es comprendida como un obstáculo para el logro de su ansiado fin. No considera que los pequeños estén facultados para realizar sus propias aspiraciones. Sólo les toca y corresponde cumplir obligaciones, al mismo tiempo que se les prohibe hacer aquello que no contribuya a la realización de lo encomendado.

El derecho a tener presenta más nítidamente el carácter de una desobediencia en tanto es afirmado como parte de una amenaza. Conviene citar el segmento en el cual se realiza dicha intimidación: 
“-¡Nada de perros aquí! ¡Ya tengo bastante con ustedes!

Enrique abrió la puerta de la calle.

-Si se va él me voy yo también"

Hay que señalar que la amenaza es una operación por medio de la cual el sujeto intimadamente hacer temer a otro. En el caso del relato que se analiza "Enrique" infunde en su abuelo el miedo (la duda) de que su intención de venta no se realice: que su falta de dinero no se colme, que su aspiración a lograrlo fracase.

Ahora bien, es de enorme importancia señalar que gracias a la formulación de la amenaza "Enrique" hace una afirmación de competencia, que también cs un acto de reconocimiento reflexivo de sus valores fisico-potenciales. $\mathrm{Y}$ un acto que implícitamente revela el conocimiento de que al anciano le falta el poder que tanto él como su hermano poseen.

Desde ese instante los niños pasan a ocupar el lugar de sujetos en cierta medida soberanos y deliberantes, capaces de decidir qué pueden-hacer y qué pueden no hacer.

La formulación de la amenaza trae como consecuencia, por otra parte, el reconocimiento implícito de la competencia fisica de los chicos por parte del abuelo, que se hace patente que éstos puedan mantener un perro:

"-Si se va él, me voy yo también.

El abuelo se detuvo. Enrique aprovechó para insistir:

-No ome casi nada..., mira lo flaco que está. (...).

Dos Santosirieflexionéc miràndō el cielos donde se condensaba la garúa. Sin decir nada solto la vara, cogió los cubos y se fue rengueando hasta el chiquero! so".

Enrique sonrió de alegría y con su amigo aferrado al corazón corrió donde su hermano.

¡¡Pascual, Pascual... Pascualito! -cantaba él abuelo"

La competencia fisica que afirman los nietos, siendo necesaria para "don Santos" se convierte en cietra forma en un objeto a negociar, en el momento en que aquéllos reclaman el reconocimiento del derecho a poseer. Se ofrece proporcionar trabajo a cambio de la aceptación de ese derecho. $\mathrm{Y}$ en tanto la propuesta es aceptada se establece un contrato entre los sujetos que se ponen en relación. Pero la aceptación del abuelo no da lugar a un estado satisfactorio. No produce bienestar sino el malestar de la frustración. Es una aceptación que por tanto trae consigo el efecto de la agresión: de la violencia verbal y fisica del abuelo contra sus nietos.

Ha de observarse que los niños, a pesar de haber logrado la posición de una sujeto en cierta medida soberano, no pierden y no aban- 
donan la condición inicial de un sujeto sumiso. Por eso, aun cuando han conseguido la afirmación y la aceptación del derecho a poseer, continúan bajo la férula del abuelo. No hay espacio aquí para tratar esta posición narrativa. Sólo ha de anotarse que tiene que ver con el hecho de que el estado de sumisión de los niños es un estado de sumisión instaurada, como el estado de soberanía del abuelo es un estado de soberanía instaurada. Es decir, se trata de estados establecidos por el orden social, y cuya modificación o transformación suponen una operación de cambio del sujeto instaurador, del Destinador no antropomorfo, o bien una operación ya sea del sujeto sumiso o del sujeto soberano en la perspectiva de una alteración de tales estados.

\section{INSATISFACCION, VENGANZA Y COMPENSACION}

El acuerdo establecido entre el abuelo y sus nietos no tiene una aceptación satisfactoria por parte del primero. El viejo admite dicho pacto con descontento. Por otro lado, "don Santos" sufre un estado de insatisfacción creciente a causa de la disminución del estado de satisfacción de su cerdo, producido por su gordura cada vez mayor, $\mathrm{y}$, en segundo lugar, por la reducción del poder físico de los niños, que los incapacita para recoger "restos de comida". Se presenta así en el anciano una triple insatisfacción, por decirlo así, que tiene por efecto una agresiva actuación, tendiente a una revancha, a un desquite con el fin de lograr la recuperación de la soberanía completa.

Un frágil y temso èquitibro. de relaciones se establece de ese modo entre los personajes. Un equilibrio hechooposible por un pacto. Pero que entraña una conseción que no anula, sin embargo, la privación del rencor, de la hostilidad.

La hostilidad implica una confrontación, un enfrentamiento entre un sujeto hostil y otro hostilizado. Ahora bien, se entiende que una lucha es una competición por la posesión de un objeto-valor que los dos sujetos contendientes aspiran tener. Pero en "Los gallinazos sin plumas" el abuelo agrede a sus nietos en pos de recuperar, como se ha dicho, su soberanía perdida, por un lado, y, otro, para conseguir una satisfacción compensatoria, mediante el castigo, por la frustración que entiende le han infrinfido los niños. En tanto que éstos no ejercen resistencia a las agresiones. En ese sentido, no enfrentan. No luchan. Aquí la confrontación es asumida sólo por el viejo. Sólo el desarrolla un comportamiento de disputa.

Hay que señalar que la agresión del abuelo no tiene como efecto inmediato una simétrica respuesta violenta por parte de los niños. Hay un acatamiento, una sumisión. Es verdad que han conseguido una cierta soberanía, como se ha visto, pero no por eso han perdido 
su condición sumisa. La soberanía concedida por el contrato, no ha eliminado la sumisión instaurada.

Pero un acontecimiento a primera vista no previsto invierte los términos de la relación. Se trata de la mordedura que el perro adoptado aplica a "don Santos", quien en respuesta lo arroja al chiquero donde es presa de la voracidad monstruosa de "Pascual". Ha de observarse en esa acción que si bien "Pedro" el perro, ocupa la posición de objeto, de posesión de los niños, en cuanto se reune con los chicos adquiere también la condición de sujeto antagonista virtual. En esa posición es, como sus amos, también víctima de las agresiones del abuelo. Como ellos también reacciona con miedo ante las feroces amenazas del anciano. Por esa razón cuando pasa al acto de la agresión, cuando muerde al viejo, ese acontecimiento puede ser susceptible de interpretarse como una actividad que lo asocia a sus dueños. Que lo coloca en la situación de sujeto cooperante. Morder es una acción mediante la cual se priva de un bien a otro sujeto. Se opera con ella una transformación disjuntiva. El abuelo pierde parte de su integridad fisica por eso. "Pedro" le infringe un malestar, le provoca un estado de insatisfacción.

Los nietos no responden a las hostilidades del viejo, pero lo hace su mascota, que opera como ayudante. De esa manera puede decirse que contribuye en buena medida a resarcir el daño que el anciano hace a los niños.

La respuesta marcada del abuelo implica a la vez la pérdida de una vida y la pérdida de un objeto querido, y la ruptura del convenio por el cual el abuelo aceptaba la poseción y el mantenimiento de "Pedro".

Esa ruptura da lugar, por último, a la confrontación final del relato, a resultas de "la cual uno de los nietos empuja al abuelo, haciéndolo caer accidentalmente al chiquero donde al final parece entrelazarse en una feroz lucha con su amado cerdo. El estado inicial de dominio /sumisión se invierte en cierta forma, pues los nietos sometidos, sublevándose contra la soberana y agresiva imposición de "don Santos" pasan a ocupar la posición de sujetos dominantes y soberanos, mientras que éste si bien no se coloca en el lugar de lo sumiso, toma el sitio de un sujeto dominado y derrotado.

La situación de sumisión de los niños tienen implicada una sanción degradante: eran valorizados por el abuelo de /putrefactos! y /animales/. Con el accidente que hace caer a "don Santos" en el chiquero, éste se aproxima prácticamente a lo /putrefacto/ y a lo /ani$\mathrm{mal} /$. En el primer caso los valores asignados a los chichos son de orden cognitivo, mientras que en el segundo los valores que, digámoslo así, adquiere el viejo son, ya se ha dicho, de orden pragmático. Uno es atribuido comunicativamente, el otro lo es operativamente. 


\section{LA CIUDAD CARNIVORA}

E relato concluye con la derrota y la sumisión de "don Santos", pero no necesariamente con el triunfo y la soberanía de los niños. Estos como su abuelo son personajes dominados y excluidos respecto de otros personajes dominantes y afirmados en el marco espacial de la ciudad. A pesar de la importancia que tienen estos últimos personajes no ha de estudiarse aquí las relaciones que con los primeros mantienen. Unicamente ha de retenerse el hecho ya señalado de que éstos tienen un estado subordinado y no incluido. Ello quiere decir que tienen la posición de un sujeto obligado a conferir al que tiene la situación dominante de un objeto-valor. Por eso los niños que se han liberado de la férula del abuelo, conservan una condición sometida respecto a la ciudad, que a la vez de constituir un espacio fisico, comprende también a la población que en el habita. Dicha población, por otra parte, forma un orden jerárquico donde dominan los más poderosos, imponiendo a los más débiles, la renuncia a sus propias pretenciones y la obligación de hacer lo que les ordenan. Hay puede decirse una cadena de relaciones de dominio y subordinación que va de los niveles superiores a los más inferiores. En esa cadena debe suponerse la existencia de un flujo de objetos-valor que se transmiten de los estratos más bajos hacia los más altos. Los niños ubicados en el punto inferior más extremo, carentes de objetos de valor externos a sí mismo, imposibilitados de ofrecer su fuerza de trabajo, con la única posesión de su cuerpo, se presentan al final del relato como objetos que la ciudad engulle, la cual aparece finalmente voraz y monstruosa, como el cerdo que es capaz de tragar cualquier cosa*. Biblioteca de Letras

\section{"Jorge Puccinelli Conversq"}

Lima, octubre de 1990.

1 Puede anotarse aqui que el querer implica una tensión vinculada a un hacer cognitivo que proyecta una realizoción, mientras que el temor implica una tensión relacionada con un hacer del orden del saber que proyecta una no realización. - Este trabajo sigue una orientación cuyas bases se hallan en los trabajo de Greimas y sus discipulos. Se han tenido presente especialmente los dos tomos de Sémiofique. Dictionaire reisomé de la théorie du langage (TI: Paris, Hachtte, 1979 y T: Paris, Hachette, 1986) de A. J. Greimas y J. Courtés y Du sens II (Paris, Ed. Du Seul, 1983) de A. J. Greimas. También ha de anotarse la imprenta de Les passions (Brusselles, Pierre Mardaga Editeur, 1986) de H. Parret y Le discours et son sujet (Paris, Klincksieck, 1984) de J-C Coquet. Menos perceptible, pero no menos importante es la huella de Mille pleteux (Paris, Les editions de minuit, 1980) de G. Deleuze y F. Guattari.

La versión de "Los gallinazos sin plumas" que se ha usado en este trabajo es la que forma parte del primer tomo de La palabra del mundo. Lima, Milla Batres,
1972 . 